\section{Near-field tsunami early warning and emergency planning in the Mediterranean Sea}

\author{
Gerassimos A. Papadopoulos, \\ Anna Fokaefs \\ Institute of Geodynamics, National \\ Observatory of Athens, Greece
}

\section{Abstract}

The new European project Near-field Tsunami Early Warning and Emergency Planning in the Mediterranean Sea (NEARTOWARN) faces the need to develop operational tsunami early warning systems in near-field (local) conditions where the travel time of the first tsunami wave is very short, that is less than 30 min, which is a typical case in the North East Atlantic and the Mediterranean Sea region but also elsewhere around the globe. The operational condition that should be fulfilled is that the time of tsunami detection, plus the time of warning transmitting, plus the time of evacuation should not exceed the travel time of the first tsunami wave from its source to the closest evacuation zone. To this goal the time to detect of the causative earthquake should be compressed at the very minimum. In this context the core of the proposed system is a network of seismic early warning devices, which activate and send alert in a few seconds after the generation of a near-field earthquake, when a seismic ground motion exceeding a prescribed threshold is detected. Then civil protection mobilizes to manage the earthquake crisis but also to detect and manage a possible tsunami through a geographical risk management system. For the tsunami detection the system is supported by tide-gauges of radar type, a database of presimulated tsunami scenarios, and a local tsunami decision matrix. The island of Rhodes in the eastern termination of the Hellenic Arc and Trench has been selected for a pilot and operational development of the local tsunami warning system given that the island is a highly popular tourist destination, historically it was hit by large tsunamigenic earthquakes and was recently the master test-site for the panEuropean FP6 tsunami research project Tsunami Risk ANd Strategies For the European Region (TRANSFER).

\section{Introduction}

Tsunamis constitute one of the important marine hazards for most of the coastal zones of the Mediterranean Sea region. ${ }^{1}$ Although the hazard takes its highest value in the central and eastern Mediterranean Sea, ${ }^{2}$ particularly along the geotectonic structure of the Hellenic Arc and Trench, it should not be ignored in the rest coastal zones of the region. Tsunami waves in the Mediterranean and its connected seas are generated mainly by submarine or coastal strong earthquakes but also by landslides and volcanic eruptions. From a zonation of relative tsunami potential it comes out that one of the most tsunamigenic zones are the western and eastern segments of the Hellenic Arc and Trench (HA-T) system (Figure 1) (Papadopoulos et al., 2014, unpublished data). ${ }^{3,4}$ It is evident also that in the Mediterranean Sea region all tsunamigenic sources are situated very close to coastal segments, that is they are of the near-field (local) type. Observational data but also results of numerical modeling have indicated that the near-field tsunamis in the Mediterranean region arrive in the nearest coasts in time intervals ranging between about 5 and $30 \mathrm{~min}^{5}$

From the tsunami risk point of view it is of great importance that according to a global tsunami statistics about $80 \%$ of victims due to tsunamis are caused within the first $1 \mathrm{~h}$ of tsunami propagation. ${ }^{6}$

The most active tsunamigenic geotectonic structure in the Mediterranean region is the HA-T system. This structure hosted the sources of the big AD 365 and 1303 tsunamigenic earthquakes (M 8), which ruptured the western and eastern HA-T segments, respectively. Very possibly they were the largest historical tsunamis ever reported in the European-Mediterranean region.$^{7-9}$ Results of numerical modeling, however, did not reproduced adequately the high tsunami amplitudes historically reported in the near-field ${ }^{10,11}$ possibly because of poor understanding of the source mechanisms and of low resolution of the bathymetry particularly in the near-shore, shallow water domain. Highly tsunamigenic is also the area between the Dodecanese island complex (Greece) and SW Turkey, at the eastern termination of HA-T, where strong destructive tsunamis caused by earthquakes were reported to hit the island of Rhodes from the antiquity up to recently (Figure 2). The very local nature of the seismic and other tsunami sources in the Mediterranean Sea region implies that for tsunami early warning in the near-field domain it is unrealistic to rely on a unique system covering the entire region. As we will show in section 4.0 even national tsunami warning centers are uncapable, at least at their present status of operation, to meet requirements for very fast alerting in cases of near-field tsunamis. As a consequence, the establishment of warning systems functioning locally but also in synergy with
Correspondence: Gerassimos A. Papadopoulos, Lofos Nymfon, Thission, PC 11810, Athens, Greece.

E-mail: papadop@noa.gr

Key words: near-field tsunami, early warning, Mediterranean Sea, Rhodes, emergency management.

Acknowledgements: the project NEARTOWARN (http://www.neartowarntsunami.com/) is supported by the DG-ECHO of the European Commission, contract no. 230301/2011/ 614039/SUB/A5. NEARTOWARN is coordinated by the Institute of Geodynamics, National Observatory of Athens, Greece, while partnership includes the University of Bologna (Italy), the University of Cyprus (Cyprus), the ACRI-ST SAS (Sophia Antipolis, France), the Univesity of Cantabria (Spain) and the Municipality of Rhodes (Greece).

Received for publication: 4 0ctober 2012.

Revision received: 29 March 2013.

Accepted for publication: 4 April 2013.

This work is licensed under a Creative Commons Attribution NonCommercial 3.0 License (CC BYNC 3.0).

(C) Copyright G.A. Papadopoulos and A. Fokaefs, 2013 Licensee PAGEPress, Italy

Research in Geophysics 2013; 3:e4

doi:10.4081/rg.2013.e4

national and regional warning or watch centers appears as the most promising. ${ }^{12}$ In Stromboli volcano, a very local system operates to meet needs for protecting population and visitors against very near-field tsunamis, which are produced by the volcanic activity in the island. The core concept of the new European project Near-field Tsunami Early Warning and Emergency Planning in the Mediterranean Sea (NEARTOWARN) is exactly to develop a pilot and at the same time operational early tsunami warning system in nearfield conditions of the Mediterranean Sea. The architecture and operational components of the pilot system are explained and discussed in next sections of this paper. Given that the island of Rhodes is the test-area for the real implementation of the pilot, local early warning system, the tsunami history of the eastern segment of the HA-T is first reviewed. It is worth mentioning that the area of Rhodes, Greece, along with Fethiye situated at the SW Turkey, was selected as the master test-site for the pan-European EU-FP6 tsunami research project Tsunami Risk ANd Strategies For the European Region (TRANSFER).

\section{Tsunami history in the East Hellenic Arc and Trench}

The earthquake and tsunami history in the 
East Hellenic Arc and Trench (EHA-T) region is documented in a long number of documentary sources which were reviewed and evaluated in several modern studies., ${ }^{213}$ What follows is only a brief summary of the EHA-T tsunami history which, however, should not be considered as being complete particularly for the time period before the $15^{\text {th }}$ century $\mathrm{AD}$; for more details one may look through the previous papers and the references cited therein.

Figure 2 illustrates sources and dates of occurrence of tsunami events that had impact documented in the area of EHA-T. ${ }^{13}$ The earliest known event was associated with the Late Bronge Age ( $17^{\text {th }}$ century BC) tsunami produced by the giant Minoan eruption in Thera volcano. The arrival of this tsunami in the area of EHA-T and as far as the eastern Mediterranean basin was documented by sedimentary deposits found in SW Turkey, e.g. in Fethiye and Didim, ${ }^{14}$ in Thera ${ }^{15}$ and in north Crete, ${ }^{14,16,17}$ as well as on the continental shelf off Caesarea Maritima, Israel $^{18}$ and verified by results of numerical simulations of the tsunami. ${ }^{19}$

In the historical period a strong earthquake struck Rhodes between 229 and 226 BC. Earlier authors, e.g. Sieberg, ${ }^{20}$ reported that a tsunami was associated with the earthquake but this is not justified by the available historical documentation. Very likely, Sieberg ${ }^{20}$ confused that earthquake with one of the subsequent tsunamigenic earthquakes occurring in the area of Rhodes, such as the AD 148 (or 142) one, which has been historically documented. Later on, a tsunamigenic earthquake was documented to destroy the northeast side of Cos island on $\mathrm{AD}$ 556. However, no impact to Rhodes Island was reported. Next was a large tsunami produced by the very high magnitude (M 8) earthquake rupturing the EHA-T segment between Crete and Rhodes on 8 August $1303 .^{8,9}$ This event, along with that of 21 July 365 which ruptured the western segment of HA-T, are among the largest tsunami waves ever reported in the Mediterranean Sea. In fact, both tsunamis flooded not only near-field localities but also remote coastal zones in the entire basin of the east Mediterranean Sea.

In the years that followed, large and destructive earthquakes associated with strong tsunamis inundating Rhodes and/or the opposite side of Asia Minor were reported to occur in 1481,1609 and 1741 . The 1481 tsunami very likely was observed as far as the coast of Israel. Tsunami sediments deposited in the coastal zone of Dalaman, SW Turkey, and attributable very possibly to the events of 1303, 1481 and 1741 were discovered and described by Papadopoulos et al. ${ }^{4,21}$ In 1851 another large earthquake caused only a moderate tsunami, which reported in Makri, modern Fethiye, but it was not reported in Rhodes. A strong earthquake on 1948 triggered a powerful but local tsunami wave that hit only Karpathos Island causing no impact in Rhodes. The large earthquake $(M=7.5)$ of 9 July 1956 that ruptured in the area of Cyclades island complex produced a large tsunami of wave amplitude of at least 12 $\mathrm{m}$ in the near field. This tsunami was reported to flood many coastal sites of the south Aegean Sea and of Crete. ${ }^{22-24}$ It was also recorded by three tide-gauges situated in Leros, south Aegean Sea, in Souda, Crete, and in Yafo,
Israel. ${ }^{22,25}$ In Rhodes the impact of the 1956 was minimal given that wave amplitude of only 0.15 m was observed there. ${ }^{22}$

No tsunami was reported to have generated from the large $M=7.2$ earthquake of 25 April 1957 and its very strong foreshock and aftershock of 24 April 1957 (M=6.8) and 26 April $1957(\mathrm{M}=6.1)$, which ruptured the segment of EHA-T offshore Rhodes. The mainshock of $25^{\text {th }}$ April was the last large $(M>7)$ shallow earth-

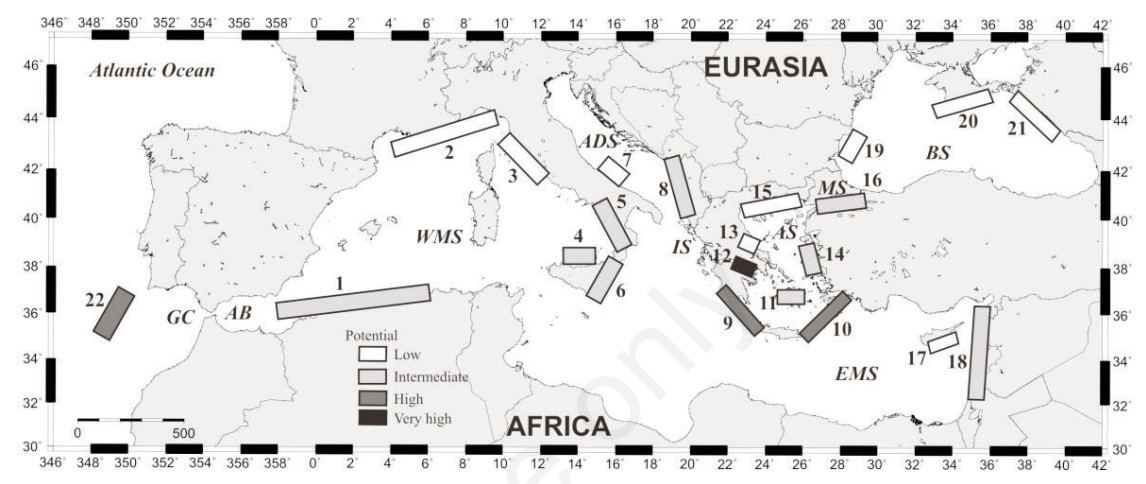

Figure 1. Tsunamigenic zones in the Mediterranean and its connected seas and their relative tsunami potential classification determined from documentary sources: WMS, Western Mediterranean Sea; GC, Gulf of Cádiz; AB, Alboran Basin; EMS, Eastern Mediterranean Sea; AS, Aegean Sea; ADS, Adriatic Sea; MS, Marmara Sea; BS, Black Sea; 1, Alboran Sea; 2, Liguria and Côte d'Azur; 3, Tuscany; 4, Aeolian islands; 5, Tyrrhenian Calabria; 6, Eastern Sicily and Messina Straits; 7, Gargano; 8, East Adriatic Sea; 9, West Hellenic arc; 10, East Hellenic arc; 11, Cyclades; 12, Corinth Gulf; 13, Maliakos Bay; 14, East Aegean Sea; 15, North Aegean Sea; 16, Marmara Sea; 17, Cyprus; 18, Levantine Sea; 19, Bulgaria; 20, Crimea; 21, East Black Sea; 22, SW Iberia (after Papadopoulos et al., 2014, unpublished data).

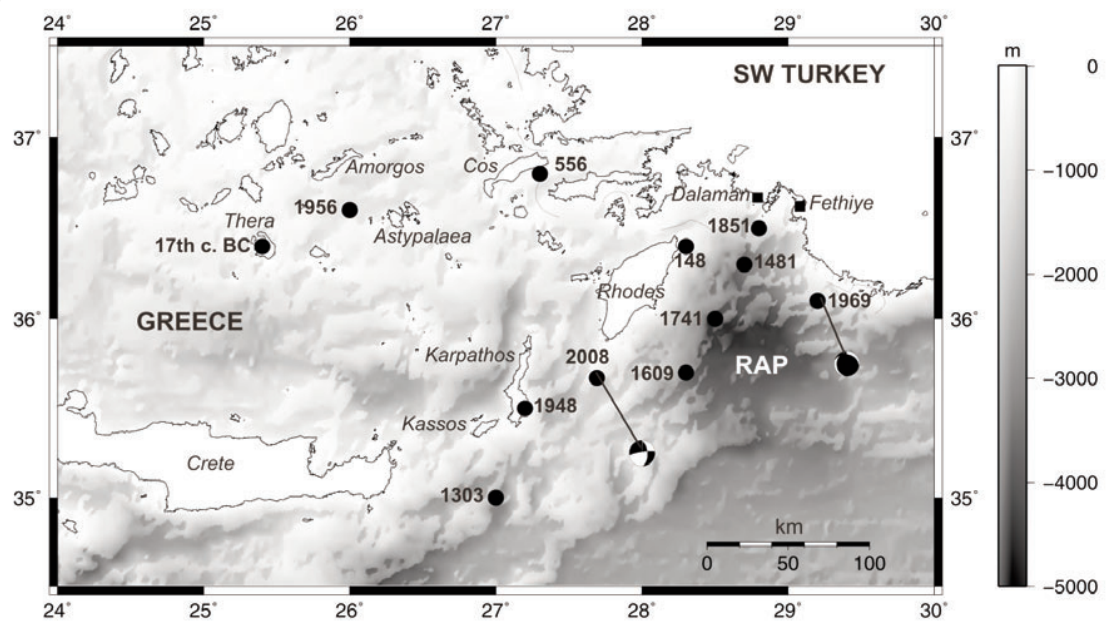

Figure 2. Epicentral locations (solid circles) and years of occurrence of the historical tsunamigenic earthquakes in the EHA-T and the surrounding areas. The source of the $17^{\text {th }}$ century BC tsunami produced by the Minoan eruption in Thera is also plotted. RAP is the Rhodes Abyssal Plain. To indicate the seismotectonics of the region the focal mechanisms (beachball diagrams) of the 1969 and 2008 strong non-tsunamigenic earthquakes are plotted (after Papadopoulos et al. ${ }^{13}$ ). 
quake that occurred until now in the area. Similarly, tsunami waves were not reported to have generated by the strong earthquakes of 28 March 1969 (M=6.6) and of 15 July 2008 $(\mathrm{M}=6.4)$ which had their epicenters offshore Rhodes to the east and to the south of the island, respectively (Figure 2). In 26 March 2002 an aseismic, local but still damaging tsunami was observed in a $2 \mathrm{~km}$-long coastal segment at the northwest side of Rhodes city. ${ }^{13}$ Eyewitnesses reported that the strong earthquake of 10 June $2012\left(\mathrm{M}_{\mathrm{w}}=6.0\right)$, which ruptured at distance of about $60 \mathrm{~km}$ offshore to east of Rhodes, caused a small sea level rise in coastal segments of east Rhodes inundating at elevation of about 1-2 m.

\section{Tsunami risk in Rhodes}

To support the need for the development of a local tsunami early warning system in Rhodes, in this section we briefly introduce the issue of tsunami risk in that island. Here we consider tsunami risk in its traditional sense ${ }^{26}$ that is risk, $R$, is a convolution of hazard, $H$, of vulnerability, $V U$, and of value $V A$, exposed to hazard:

$$
R=H^{*} V U^{*} V A
$$

As regards hazard, that is the physical attribute only, from the review of the tsunami history of Rhodes it comes out that it is serious at the extend it is related to tsunami generation associated with local, seismic tsunami sources mainly in or around the Rhodes Abyssal Plain (Figure 2). The epicentral areas of these earthquakes are situated at distances of no more than about $100 \mathrm{~km}$ from the Rhodes capital city, which occupies the north edge of the island. By considering that the tsunami velocity is given by the formula $v=(g h)^{1 / 2}$, where $g$ is the gravity acceleration, and by adopting that the ray propagation theory is a good approximation for the calculation of tsunami travel times, it was found that the inverse travel time from several forecast points to the tsunami sources in or around the Rhodes Abyssal Plain, that is at epicentral distances of not exceeding $100 \mathrm{~km}$, is on the order of 15 min.,27 This implies that the tsunami sources around Rhodes are clearly of the nearfield type. On the other hand, tsunami hazard related to distant sources, such as for example the 1303 one is low from the probability point of view but not negligible.

In the historical record of tsunami events occurring in the area of Rhodes one may find that before the $14^{\text {th }}$ century only two events were reported. On the contrary, from the $14^{\text {th }}$ century and afterwards the frequency of occurrence increased drastically which certainly reflects reporting completeness. Assuming that the tsunami history of Rhodes is complete in the last eight centuries or so, we may calculate roughly the tsunami mean repeat time. In fact, in the time period of about 710 years that have passed after AD 1300 Rhodes was hit by three, well-documented strong tsunamis that are those of 1481, 1609, and 1741. The 1303 wave likely hit Rhodes, as one may conclude from the tsunami sediment layers found in Dalaman, but this is not well documented from historical sources. On the contrary, the aseismic but local and of moderate size tsunami of 2002 is well documented. For the calculation of the mean repeat time one may consider either only the three well-documented strong waves of $1481,1609,1741$ or to add the wave that possibly affected Rhodes on 1303 or even the aseismic one of 2002 . Then, the mean repeat time ranges from $710 / 3=237$ to $710 / 4=178$ or to $710 / 5=142$ years. Alternatively, assuming completeness in the tsunami record only from 1450 onwards, then we find that the repeat time is $560 / 3=187$ or $560 / 4=140$ years. As regards only strong tsunamis caused by earthquakes it is of importance to note that the last, large tsunamigenic earthquake occurred on 1741, which underlines the relatively long time interval that has passed without strong tsunami occurrence in the area of Rhodes. The vulnerability as well as the value exposed to hazard is strongly time-dependent attributes due to the tourist activities, which increase highly in summer season that is from May to October. In the same season, day-night dependency of the vulnerability and of the value exposed to tsunami hazard is strong too. These two parameters, however, are also space-dependent given that most of the population and human activities are concentrated in and around the capital city that is in the northern part of the island. The permanent population in the island is about 117,000 that during the summer peak season roughly doubles.

\section{Minimizing early warning time}

The challenges for efficient tsunami early warning systems have been made the subject of several discussions among the scientific and technological communities particularly after the experience of the big Tohoku (Japan) tsunami event of $2011 .{ }^{28}$ The need for tsunami early warning in the near-field (or local) domain has been internationally discussed..$^{29,30}$ One definition for near-field tsunamis is that wave travel distances are of a similar order of magnitude to the earthquake rupture length. ${ }^{31}$ Such physical preassumptions were adopted for the development of the German Indonesian Tsunami Early Warning System (GITEWS) on the basis of the correct characterization of the earthquake rupture, including of the seismic slip distribution, based on seismological and global positioning system records. It is expected that information of this type will be available 5-10 min after the event at best. For earthquake magnitude of about 7.0 or 7.2, which is the case of Rhodes large earthquakes such as the 1957 one, the rupture length is about $80 \mathrm{~km}$, thus justifying our assumption that near-field for Rhodes means tsunami travel distances not exceeding $100 \mathrm{~km}$.

In near-field conditions the operative efficiency of a tsunami warning system depends on the times needed for seismic signal communication, $t_{S}$, and for evacuation, $t_{E}{ }^{32}$ Therefore, the next relation should be realized:

$$
t_{t r}>t_{S}+t_{E}
$$

where $t_{t r}$ is the first tsunami wave travel time from the source to the closest settlement.

Let us examine now the current status of the Hellenic National Tsunami Warning Center (HLNTWC) in Greece, a country which is still in the stage of building up its national system and at the same time is in an interim stage of operational function and candidate to act as one of the Tsunami Watch Providers for the North East Atlantic and Mediterranean Tsunami Warning System (NEAMTWS) under the supervision of the Intergovernmental Coordination Group of the Intergovernmental Oceanographic Commission (ICG/IOC) of UNESCO. No operational experience exists in Greece for the moment as it exactly happens with all the other countries of the Mediterranean region; yet France has experience in tsunami warning in the French Polynesia. In the current scheme, the Institute of Geodynamics of the National Observatory of Athens (NOA) is responsible for the 24/7 earthquakes monitoring of the country and charged by law to operate the HLNTWC. From the point of view of monitoring sea level changes, the tide-gauge network suitable for the record of tsunamis is still in the very beginning of its development. On the other hand, NOA is a public research center which practically means that it is responsible for the monitoring of the earthquake and tsunami phenomena but is not authorized to disseminate tsunami early warning information to the general public or to selected target groups. This duty belongs to the General Secretary for Civil Protection (GSCP) of the country and, therefore, NOA transmits tsunami warning or information bulletins to GSCP.

Under these conditions let us assume that a strong earthquake, say of magnitude around 7 , takes place in the area offshore Rhodes and at distance not exceeding about $100 \mathrm{~km}$. If a tsunami generates it would be certainly of the near-field type. Then, from the operational point of view the crucial question is how it is possible to warn local population in Rhodes and what are the time constraints to do so. This very important issue is examined in details in the next lines.

The first stage of the warning procedure is for NOA to determine preliminary earthquake 
focal parameters, that is the origin time, the epicentral location, the focal depth and the magnitude. This can be done either automatically by the seismograph system within about 3-5 min or manually by seismologists within about 10-15 min from the earthquake generation at best. Automatic solutions suffer from errors that usually are larger than the manual ones. As soon as the earthquake event is determined, NOA has to reach a decision if the earthquake bears potential for tsunami generation and to transmit the information to the civil protection. A tool applicable for the moment is the decision matrix adopted in the last years by the ICG/NEANTWS/IOC/UNESCO for the entire Mediterranean region, that is a set of empirical rules combining the location, magnitude and focal depth of the earthquake to make decision if a particular earthquake event is capable to produce tsunami or not and very roughly what is the expected size of the tsunami event. The NEAMTWS Interim Operational User's Guide allows also the case where tsunami alert messages can be based on expected tsunami amplitudes instead of expected arrival times or distances from the epicenter especially in case of improved numerical forecast models/pre-calculated scenario databases. A dedicated Tsunami Analysis Tool has been already installed in several NEAMTWS centers, including NOA, for future operational purposes.

The next stage is that the civil protection should release an early tsunami warning that should reach local population and visitors in Rhodes as soon as possible. Then the local civil protection unit and other authorities have to mobilize with the aim to manage the crisis, while the population should evacuate from coastal zones to higher grounds.

The above procedure of warning clearly implies that each one of the parameters $t_{S}$ and $t_{E}$ in Eq. (2) is composed by more than one time components. Seismic signal communication incorporates the time needed for the determination of the earthquake focal parameters, $t_{S D}$, the time needed for the tsunami decision-making, $t_{T D}$, as well as the time, $t_{S T}$, needed for the transmission of the earthquake information and of the result of tsunami decision to the operational center of the civil protection. In addition, the time for evacuation incorporates another two time components. The first is the time, $t_{W T}$, needed to transmit warning information from the civil protection to the population. Finally, after transmitting this information there is need to allow for some time to respond for real evacuation, $t_{E V}$. Then, from the very operational point of view Eq. (2) becomes:

$$
t_{t r}>t_{S D}+t_{T D}+t_{S T}+t_{W T}+t_{E V}
$$

Assuming that under optimum conditions the earthquake information as well as the tsunami decision are transmitted to the civil protection automatically as soon as the earthquake determination has been performed, then Eq. (3) is reduced to:

$$
t_{t r}>t_{S D}+t_{W T}+t_{E V}
$$

We adopt that the time, $t_{S D}$, needed for the earthquake determination is $5 \mathrm{~min}$ at minimum, and the time, $t_{W T}$, needed for the civil protection to issue and disseminate early tsunami warning is another $5 \mathrm{~min}$ at best. Time, $t_{E V}$, for the population to receive and understand correctly the warning information and to run away for real evacuation takes 15 min at the best. Finally we get $t_{t r}>25 \mathrm{~min}$. However, as already pointed out $t_{t r}$ is on the order of $15 \mathrm{~min}$. Therefore, the time needed for tsunami warning and real evacuation for an ideally performing central tsunami warning system in Greece nearly doubles the time needed for the first tsunami wave arrival. This result underlines the urgent need to compress drastically the time needed for warning and real evacuation by developing a local tsunami early warning system in Rhodes. Before we present the plan of the project NEARTOWARN for the development of such a local system, the experience gained by the 11 March 2011 very large near-field tsunami in Tohoku, NE Japan, is briefly reviewed.

\section{The Japanese experience: tsunami arrival in 25 minutes}

To evaluate how a real tsunami early warning system operating in near-field conditions is capable to satisfy Eq. (4), the great Tohoku tsunami that hit east Japan on 11 March 2011 (14:46, Japan time) was taken as a reference case. According to Kamigaichi ${ }^{33}$ of the Japan Meteorological Agency (JMA), seismic early warning for an earthquake of $M=7.9$ was issued by JMA through the public broadcasting system of Nippon Hoso Kyokai (NHK) in about $1.5 \mathrm{~min}$ after the earthquake generation. A decision for a large tsunami of 3 to $6 \mathrm{~m}$ height was derived from a data base of pre-simulated tsunami scenarios and early warning was disseminated through the NHK system 3 min from the earthquake generation. A first sea level rise of about $0.2 \mathrm{~m}$ arrived in some localities within 10 to $15 \mathrm{~min}$ but the nature of it is not clear. Certainly that sea level motion was not destructive, possibly only damaging, and did not represented the big tsunami that arrived later but very possibly it was the result of the massive co-seismic subsidence of the east coast of NE Honshu. The first tsunami wave arrived about 25 min from the earthquake origin time and in some coastal localities it was of much higher amplitudes than the forecasted ones. This means that the first warning was issued on time but underestimated dramatically the tsunami height, which is explained by that the first earthquake magnitude was also underestimated due to saturation of the seismic records. When real tsunami records from tsunameters as well as very broadband seismic records became available, the tsunami warning was revised about $28 \mathrm{~min}$ after the earthquake origin time with revised tsunami warning parameters fitting much better the wave heights and arrivals observed.

From the point of view of the time that the first tsunami warning was issued one may argue that the warning was successful. In fact, we see that in Eq. (4) we get $25 \mathrm{~min}>>3 \mathrm{~min}$. However, the evacuation of population only partly performed well. Several populations never evacuated, while others were delayed in evacuation even in coastal segments where the first tsunami arrived about $1 \mathrm{~h}$ after the earthquake origin time. Problems with the evacuation often were due either to the content of the warning message itself or to the announcement that the first wave observed was low. For example, Kamigaichi ${ }^{33}$ reported that the warning for an expected tsunami of 3 $m$ caused delay in evacuation since many residents considered that they were safe. On the other hand, the announcement that the first tsunami amplitude observed was only $0.2 \mathrm{~m}$ caused also delays or even interruptions in the evacuation procedures. The negative response to evacuation resulted in the dramatic increase of the number of victims.

The case of Natori city, examined in details by its mayor Sasaki ${ }^{34}$ is extremely illuminating as regards real problems for the transmission of tsunami warning information to local communities and for the effective evacuation. In Natori the first tsunami arrival was noted on 15:51 with wave height exceeding $10 \mathrm{~m}$. However, due to the earthquake shaking the municipal disaster management radio communication network suffered from power supply short-circuit, while blackout was caused to the local TV system. The warning means which performed well included mobile radio, public information by firefighting team vehicles, public information provided by the neighborhood association and the voluntary disaster prevention organization as well as calling from neighbors. In addition, the local sound machine did not sound since some of its metal pieces fell onto the power supply of the radio transmitter on the roof, due to the strong earthquake shaking, and then it short-circuited.

After these experiences in Natori, Sasaki ${ }^{34}$ recommended that in order to get communication means, which will be usable at the time of a great disaster, one might rely on low technology rather than on high technology. This is consistent with one of the lessons learned according to Koshimura ${ }^{35}$ who concluded that 
there are still limitations on the reliability of science and technology, which is in use for the tsunami early warning in near-field conditions. He supported that in these conditions the tsunami warning information is useful to let residents know that they are in danger, but it does not guarantee their safety. He also emphasized that under such conditions there is no need to wait for official information, a practice that certainly could comprise the evacuation time. From this point of view, a perfect example was presented by Suenaga ${ }^{36}$ who showed that our own decision and action based on correct information and knowledge could save our lives through the dogma tsunami ten-den-ko, that is save your life by yourself. He presented an excellent example from the Kamaichi city where many students evacuated very effectively based on their good education and training as well as on their own action and tsunami ten-den-ko practice at the time of the tsunami threat. It should be noted, however, that the tsunami ten-den-ko practice does not reduce the value of the early warning systems and does not substitute such systems given that it falls in the response stage following the warning. Therefore, the tsunami ten-den-ko practice should be viewed only in synergy to warning systems.

From the recent Japanese experience briefly outlined above one may conclude that in the chain determine physical parameters - warn people-evacuate people, there are at least two seriously weak links. The first concerns the large uncertainties involved in the earthquake parameter determination and in the parameters of the expected tsunami. The second is about the very practical implementation of the system that is about the response of population to evacuation. To improve the Japanese tsunami warning system for local tsunamis, JMA decided to revise and make simpler the procedure as explained officially and in details in the report of Kamigaichi. ${ }^{33}$ According to this report, the first tsunami warning should be disseminated in $3 \mathrm{~min}$. In case it is likely to underestimate earthquake magnitude, the first warning should be based on the assumed maximum magnitude of the area, while the estimated tsunami amplitude should be mentioned only qualitatively as an emergency message. Considering the scatter of tsunami amplitude involved but also for closer linkage of warning to hazard maps, it was also decided to reduce the number of levels of estimated tsunami amplitude from 8 to 5 . Finally, even though the first observed tsunami amplitude is too small it should be not reported in numbers to avoid underestimation of the threat by the residents.

One of the critical lessons learned from the Tohoku 2011 experience is the underestimation of the earthquake size and because of this of the tsunami size too. Another critical point is that many residents didn't evacuated because of misunderstanding of the warning messages. The third is that for those who decided to evacuate in response to the early warning evacuation was not an automatic procedure. On the contrary, the time needed for real evacuation was much longer than one may expect. In view of the above serious problems, the decision of JMA to revise warning procedures making them simpler and more qualitative than they were before appears quite realistic.

The Japanese experience: tsunami arrival in 5 minutes

A good example of a very local tsunami comes from the Okushiri island tsunami case of 13 July 1993 in the north side of the Japan Sea. The earthquake measuring $M=7.2$ occurred in Japan Sea at a distance of only 70 $\mathrm{km}$ offshore west of Hokkaido island at 22:17. On 22:22 the NHK system announced the earthquake focal parameters along with a tsunami early warning message. The first, destructive tsunami wave arrived just at the announcement time practically leaving time for evacuation not due to the warning but only due to the tsunami ten-den-ko practice. In fact, many residents reacted as soon as they felt the strong earth shaking. The new practice introduced by JMA after the Tohoku event of 2011 certainly improves the early tsunami warning capabilities for tsunamis arriving only within 5 min from the earthquake origin time.

\section{The concept of NEARTOWARN Project}

A variety of seismic and non-seismic nearfield tsunami sources threaten coastal communities in the NEAM region. Databases of tsunamigenic sources were created in the context of previous EU research projects, TRANSFER being the most recent (2006-2009). Although tsunami scientists in the EuropeanMediterranean region do not believe that a complete knowledge of the tsunami sources is in place, the already accumulated knowledge is still of great value. The information compiled in scientific databases, however, has not been disseminated widely for the benefit of civil protection for the purpose of risk mitigation and emergency planning actions. In this view, one of the deliverables of the NEARTOWARN project aims to characterize and map the near-field tsunami sources in the NEAM region in a way that will be useful to civil protection authorities for understanding the level and type of risks associated with such tsunami sources. This was done by calculating through ray propagation theory the time needed for the first tsunami wave to arrive from a long number of tsunami sources to a long number of forecast points in the coastal zones of NEAM. ${ }^{5}$ The next step is to produce a comprehensive inventory of near-field tsunami sources and of forecast points in the NEAM region with the aim to support civil protection operations. A parallel activity is to standardize requirements for a database of pre-simulated tsunami waves.

The main goal of NEARTOWARN project, however, is to close the gap between the basinwide watch services and the regional warnings scheduled to be provided by the NEAMTWS and the national centers, respectively, and the need to warn for near-field tsunamis. To this aim the architecture of an early warning system for near-field tsunamis is described in the next subsection. The real construction and implementation of such a system in the test-site of Rhodes is in each final stage. The system will also serve as a pilot for other areas, which are threatened by near-field tsunamis in the NEAM region and beyond. Rhodes was selected for a number of reasons: historically, it was hit by near-field, strong earthquakes and tsunamis and, on the other hand, it was the master testsite for the research project TRANSFER. In addition, that island represents one of the highly tourist destinations, a fact that increases the tsunami risk particularly during the tourist peak season giving a European and an international dimension to the tsunami risk in Rhodes.

\section{Architecture of an early warning system for} near-field tsunamis

An early warning system responding to tsunami wave travel times of not exceeding 30 minutes, that is in near-field conditions, which is the typical case in the NEAM region including the NEARTOWARN test-site of Rhodes, should be capable to satisfy Eq. (4). The only compressable parameters in this relation are $t_{S D}$ and $t_{W T}$ since they are based on technological improvements. On the other hand, since no experience exists on tsunami warning and evacuation in Europe and in the Mediterranean, including Greece and Rhodes, we do not believe that in the foreseeable future it would become possible to decrease the time for real evacuation below the limit of $15 \mathrm{~min}$ suggested earlier, which is a quite optimistic assumption anyway. This implies that one should minimize the time needed for the detection of a local, potentially tsunamigenic strong earthquake as well as the time for the initiation of emergency procedures. To make such possibilities practically applicable for the benefit of civil protection, planning for emergency and warning management should be elaborated too. As a consequence, an early warning system for near-field tsunamis in the Mediterranean Sea should be consisted by three main components: i) instrumental network for immediate earthquake detection and alert; ii) instrumental network and computational tools for early tsunami detection; iii) planning for early warning, emergency and crisis management. The operational output 
expected incorporates benefits for immediate emergency response for both near-field earthquakes and tsunamis, thus satisfying requirements for a multi-hazard approach as regards tsunami warning systems. Components i) and ii) represent the upstream section of the system. The downstream section, including the communication of the warning message to the population, is represented by the component iii). The flow chart in Figure 3 illustrates the basic architecture of the early warning system for near-field tsunamis while each one of the three components of the system are explained in the next subsection.

\section{Seismic early warning}

The physical principle to initiate immediate response to an earthquake is the difference in arrival of the secondary (S) wave after the primary (P) wave. This difference increases with the increase of the epicentral distance. Appropriate seismic alert devices (SAD's) are able to detect both $\mathrm{P}$ and $\mathrm{S}$ waves. The recorded characteristics of the $\mathrm{P}$ wave permits drawing of conclusions as to the strength of the following $S$ wave and, consequently, to the expected level of ground motion expressed in terms either of peak ground acceleration or of macroseismic intensity. If a pre-selected threshold of ground motion is exceeded, a SAD system may trigger optical and acoustic alarms in pre-selected localities (e.g. civil protection unit, fire brigade unit). The threshold level of ground motion is selected to correspond to an earthquake of a given magnitude threshold and occurring within a given maximum distance. Such SAD systems, called sectylifePatron ${ }^{\circledR}$, were produced as a technological development by the company sectyelectronics GmbH (Castrop-Rauxel, Germany), and tested in collaboration with GFZ (GeoforschungsZentrum, Potsdam, Germany), the coordinating institute of the EU-FP6 research project Seismic Early Warning for Europe (SAFER, 2006-2009) and one of the leading geophysical institutes in Germany and Europe. Such devices were also tested in NOA under the supervision of the first author in the frame of SAFER. Devices of sectylifePatron ${ }^{\circledR}$ (sectyelectronics $\mathrm{GmbH}$ ) type have been installed for operational use in several seismogenic countries around the world including Greece. Given that the earthquake detection is the core function of a tsunami warning system, the innovative idea for the early warning for near-field tsunamis is to use a network of SAD's detecting immediately local strong earthquakes that could be causative of nearfield tsunamis in a target area. An initial network of four SAD's with 8 sensors is planned to install in Rhodes in the frame of NEARTOWARN project. Each sectylifePatron ${ }^{\circledR}$ (sectyelectronics $\mathrm{GmbH}$ ) device, which is planned to install in selected buildings of Rhodes, con- sists of one master unit and one slave unit which are placed in different installation points of the same building. Seismic alarm happens only when both the master and slave units are triggered simultaneously, thus securing that the false alarm rate becomes minimal. Each one of the master and slave units is equipped by a number of sirens and optical signal devices. An optimization study was performed as regards the triggering thresholds of SAD's for strong earthquakes having their epicenters at a distance up to about $100 \mathrm{~km}$ from the city of Rhodes. Empirical relations between earthquake magnitude on one hand, and peak ground acceleration and macroseismic intensity on the other, were used to optimize triggering thresholds. The selection of four buildings in Rhodes city and in nearby communities were already selected for the installation of four SAD's. They are buildings belonging to critical authorities for emergency management such as the civil protection authority, the fire brigade unit and municipality services.

As soon as a SAD unit has been activated by a strong earthquake, the device resets automatically in $3 \mathrm{~s}$ thus becoming ready to receive new triggering signal. SAD units do not require special maintenance or needs. A usual minor problem is that they may shut down if energy supply is interrupted. However, SAD units are autonomous from the energy supply point of view. In fact, normally they get energy

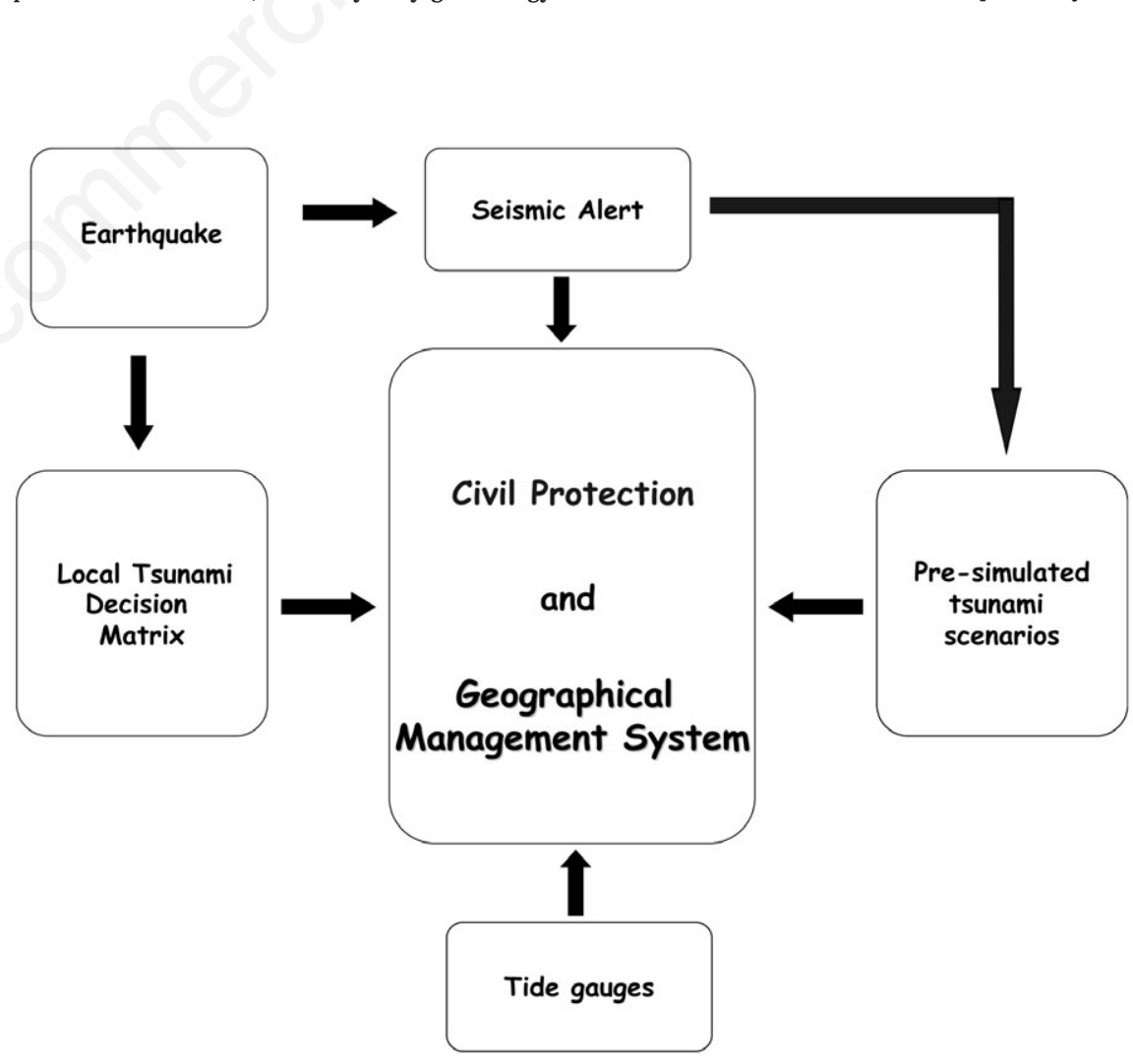

Figure 3. Flow diagram of the warning system for near-field tsunamis scheduled to develop in the island of Rhodes for the Near-field Tsunami Early Warning and Emergency Planning in the Mediterranean Sea (NEARTOWARN) project. from the central power supply system but in case of strong earthquake or other emergency they are self-supported for several hours while are further supported by uninterruptible power supply devices. Besides, since SAD units will be installed indoors in buildings of emergency authorities operating $24 \mathrm{~h}$ their continuous inspection is secured, thus they are not susceptible to bandalism or other damage threats.

Early detection of a strong earthquake implies initiation of emergency procedures only within few seconds from the earthquake generation. Then, civil protection and other local authorities are able to mobilize immediately and start actions aiming to initiate emergency procedures well before an automatic or manual preliminary determination of the earthquake parameters will be available by the central seismograph center of NOA some minutes after the earthquake generation.

\section{Tsunami early warning}

The very first tool that is today available in the NEAMTWS region for informing authorities and communities about the potential for tsunami occurrence after a strong earthquake is the decision matrix (DM) elaborated by groups of specialists working within the ICG/NEAMTWS/IOC/UNESCO. A DM tool has been developed for North East Alantic and another for the Mediterranean. Since the Mediterranean DM was based primarily on 
earthquake and tsunami data of the Greek area, it is expected that it will not be absolutely appropriate for use in a local scale. In a recent paper ${ }^{38}$ the applicability of the Mediterranean DM was tested for tsunamis occurring in the Italian territory. It was found that the actions prescribed in this DM are adequately applicable only in the 45\%-55\% cases, the overestimations being of $37 \%$ while underestimations are the rest. For the development of a local DM tool in the area of Rhodes the past earthquake and tsunami history will be taken into account. From this point of view it is of importance that strong or moderate tsunamis are known to have been produced only by local (distance not exceeding $100 \mathrm{~km}$ ), shallow, very strong earthquakes, namely those of AD 1481, 1609, 1741 and 1851, all being of estimated magnitudes around 7 or more. These magnitudes, however, suffer from large error, which may be up to 0.5 . The historical earthquake catalogue of the area, summarized by Papadopoulos et al.,13 is very likely complete since 1450 as regards earthquakes of magnitude around 6.5 and over. Supplementary tools include additional devices, databases and procedures, such as tide-gauges, and retrieval of appropriate tsunami scenarios from a database of pre-simulated tsunamis, all scheduled to be developed during the execution of the project. From a preliminary site inspection it was already decided to install two radar-type tidegauges along the eastern coastal segment of Rhodes, which is facing trenchwards, that is to the area of the main tsunamigenic sources threatening Rhodes. A third tide-gauge will be installed possibly to one of the nearby islands, an issue which is under discussion with the local authorities. The records of the sea level changes will be transmitted to NOA as well as to the civil protection office of Rhodes in real-time via satellite Internet technology. The production of pre-simulated tsunami scenarios will be based on the past earthquake and tsunami history of the area. To speed up procedures, provision has been taken that as soon as a SAD unit activates a signal will be send for automatic sirene alerting in the coastal zone and for running computer programs retrieving pre-computed tsunami scenarios. Future possibilities include installation of additional SED's and tide-gauges as well as tsunameters offshore Rhodes, and surveillance cameras along coastal zone segments for control immediately after a strong earthquake.

The NEARTOWARN system, however, does not incorporate early detection of tsunamis caused by aseismic landslides, which are still out of control. Nevertheless, aseismic tsunamis are locally powerful and, therefore, quite hazardous. For example, the last case of 26 March 2002 in Rhodes was characteristic. To contribute in this critical aspect an investigation of the prospects of the hydroacoustic technology for the early detection of such tsunamis will be examined as a promising future tool.

\section{Emergency planning for tsunami early warning}

For the downstream component III of the system, that is for emergency planning and warning management, a hypothetical worst tsunami disaster scenario will be produced and the emergency needs will be determined not only for the warning management but also for the long-term planning. Since no operational experience exists in the region of NEAM, the experience gained in Japan particularly after the great tsunami of 11 March 2011 becomes of substantial importance for the development of a geographical management system (GMS) with application in the test area of Rhodes. The objective is to organize an emergency plan meeting crisis management needs of the civil protection unit including preparedness actions in the long-term sense and prospects for the sustainability of the warning system.

A series of valuable lessons learned in Japan after the devastating near-field tsunami of 2011 certainly merits utilization in the organization of a GMS for NEARTOWARN. The first is the determination of the most appropriate low-technology means for warning communication as well as the elaboration of operational manuals which should not be very detailed allowing for flexibility in action during the crisis. ${ }^{34}$ The Tohoku 2011 tsunami inundated many coastal areas beyond the pre-determined hazard zones. Therefore, there is need to link hazard zonation map and warning system in the sense that the area outside the hazard zone does not guarantee safety. ${ }^{35}$ In Rhodes, tsunami hazard zones determined by research groups who worked for the TRANSFER project will be taken into account. In Japan it was observed also that over $2 \mathrm{~m}$ tsunami flow depth potentially causes serious damage on houses, while high-rise/robust reinforced concrete buildings withstand and can be used for vertical evacuation. ${ }^{35}$ Selection and designation of evacuation buildings in Rhodes is up to the decision of the local civil protection office. Other lessons are of great importance for the education program too. ${ }^{35}$ One of them says that in order to build up tsunami resilient communities, never forget the past earthquake and tsunami memories of the area. In view of this NEARTOWARN will provide the civil protection of Rhodes with a comprehensive earthquake and tsunami history of the area. Another lesson is that the tsunami early warning in the nearfield domain is in place to remind that we are in danger, but it does not guarantee our safety. Therefore, the tsunami ten-den-ko/save your life by yourself concept constitutes an additional important educational lesson. ${ }^{36}$ In the same spirit is the concept of Earthquake! Tsunami! Evacuate Right Away! developed for a tsunami that may attack within only a few minutes after a large earthquake in the Tokai region. ${ }^{38}$ It is simple and understandable by everybody. Finally, a series of very simple but practical guidelines who save lives, include instructions such as evacuating by car creates confusion, you can't carry all of your valuables, when water reaches you, hurry to the nearest tall building and check the location of evacuation buildings in advance. $^{38}$

\section{Conclusions}

The coastal zones of the North East Atlantic and Mediterranean region are threatened by near-field (local) tsunami sources producing tsunami arrivals ranging from 5 to less than 30 min. To meet the needs for tsunami early warning in near-field conditions, the NEARTOWARN project aims to develop a local warning system in Rhodes, which was hit by local tsunamis several times in the past. The system is composed by three main components: i) instrumental network for immediate earthquake detection through seismic alert devices; ii) a tide-gauge network and computational tools for early tsunami warning; iii) planning for the emergency and warning management through a GMS. Future improvements may include installation of tsunameters offshore Rhodes as well as coastal surveillance cameras for the control of the coastal segment. Components i) and ii) represent the upstream section of the system. The downstream section, including the communication of the warning message to the population, is represented by the component iii). The valuable experience gained in Japan after the 2011 great tsunami should be extensively taken into account. The operational output expected incorporates benefits for immediate emergency response for both near-field earthquakes and tsunamis. Such a system could be also installed for local tsunami warning in other areas of the Mediterranean and beyond.

\section{References}

1. CIESM Workshop Monographs, no. 42. Marine geo-hazards in the Mediterranean. Nicosia (Cyprus), 2-5 February 2011. Available from: http//www.ciesm.org/ online/ monographs/Nicosia.html.

2. Papadopoulos GA. Tsunamis. In: Woodward $\mathrm{J}$, ed. Physical geography of the Mediterranean. Oxford: Oxford University Press; 2009. p 493-512.

3. Papadopoulos GA, Fokaefs A. Strong tsunamis in the Mediterranean Sea: a re-evaluation. ISET J Earthq Tech 2005;42: 159-70.

4. Papadopoulos GA, Minoura K, Imamura F, et 
al. Geological evidence of tsunamis and earthquakes at the Eastern Hellenic Arc: correlation with historical seismicity in the eastern Mediterranean Sea. Res Geophys 2012;2:e12.

5. Zorrilla Aniel-Quiroga I, González Rodríguez M. Data bases, maps and inventories for nearfield tsunami sources in the North East Atlantic and Mediterranean Sea, IH Cantabria Report. NEARTOWARN project July 2012. Available from: http//www.neartowarntsunami.com/public_documents.aspx)

6. Gusiakov V. Chapter 2: Tsunami history. In: Bernard EN, Robinson AR, eds. The Sea, vol. 15: Tsunamis. Cambridge, MA: Harvard University Press; 2009. p 23-53.

7. Guidoboni E, Comastri A, Traina G. Catalogue of ancient earthquakes in the Mediterranean area up to the 10th century. Bologna: Storia Geofisica Ambiente; 1994.

8. Guidoboni E, Comastri A. The large earthquake of 8 August 1303 in Crete: seismic scenario and tsunami in the Mediterranean area. J Seismol. 1997;1:55-72.

9. Papadopoulos GA. A Seismic history of Crete: earthquakes and tsunamis, $2000 \mathrm{BC}-2011$ AD. Athens: Ocelotos Publications; 2011.

10. Tinti S, Armigliato A, Pagnoni G, Zaniboni F. Scenarios of giant tsunamis of tectonic origin in the Mediterranean. ISET $\mathbf{J}$ Earthq Tech 2005;42:171-88.

11. Loritto S, Tiberti MM, Basili $\mathrm{R}$, et al. Earthquake-generated tsunamis in the Mediterranean Sea: scenarios of potential threats to Southern Italy. J Geophys Res 2007;113:B01301.

12. Papadopoulos GA. NEARTWARN - A proposal for near-field tsunamis in the Mediterranean Sea: potential assessment, early warning and risk mitigation. In: CIESM Workshop Monographs, no. 42. Marine geo-hazards in the Mediterranean. Nicosia (Cyprus), 2-5 February 2011. pp 121-124. Available from: http//www.ciesm.org/online/monographs/Nic osia.html

13. Papadopoulos GA, Daskalaki E, Fokaefs A, Giraleas N. Tsunami hazard in the Eastern Mediterranean: strong earthquakes and tsunamis in the East Hellenic Arc and Trench System. Nat Hazard Earth Syst Sci 2007;7:57-64.

14. Minoura K, Imamura F, Kuran U, et al. Discovery of Minoan tsunami deposits. Geology 2000;28:59-62.

15. McCoy F, Heiken, G. Tsunami generated by the Late Bronze Age eruption of Thera (Santorini), Greece. Pure Appl. Geophys 2000;157:1227-56.

16. McCoy FW, Papadopoulos, G. Tsunami generation during the Late Bronze Age Eruption of Thera: Evidence from Tsunami Deposits on Thera, Crete, West Turkey and the Deep Sea. Am J Arch 2001;105:258-9.

17. Bruins HJ, MacGillivray JA, Synolokis CE, et al. Geoarchaeological tsunami deposits at
Palaikastro (Crete) and the Late Minoan IA eruption of Santorini. J Arch Sci 2008;35:191212.

18. Goodman-Tchernov BN, Dey HW, Reinhardt EG, et al. Tsunami waves generated by the Santorini eruption reached Eastern Mediterranean shores. Geology 2009;37:943-6.

19. Novikova T, Papadopoulos GA, McCoy F. Modelling of tsunami generated by the giant late Bronze Age eruption of Thera, South Aegean Sea, Greece. Geophys J Int 2011;186:665-80.

20. Sieberg A. Untersuchungen über Erdbeben und Bruchschollenbau im östlichen Miettelmeersgebiet. Denkschr Mediz Naturwiss Gesell Jena 1932;2:184-224.

21. Papadopoulos GA, Imamura F, Minoura K, et al. Strong earthquakes and tsunamis in the East Hellenic Arc and Trench System. Geophys Res Abstracts 2005;6:EGU200503212.

22. Galanopoulos AG. [The seismic sea-wave of 9 July 1956.] Praktika Acadimias Athinon 1957;32:90-101. [In Greek].

23. Ambraseys NN. The seismic sea wave of July 9, 1956, in the Greek Archipelago. J Geophys Res 1960;65:1257-65.

24. Papadopoulos GA, Imamura F, Minoura K, et al. The 9 July 1956 large tsunami in the South Aegean Sea: compilation of a data basis and re-evaluation. In: Papadopoulos GA, Satake K, eds. Proc. 22nd Int. IUGG Tsunami Symposium, 2005 June 27-29, Chania, Crete, pp 173-180.

25. Beisel S, Chubarov L, Didenkulova I, et al. The 1956 Greek tsunami recorded at Yafo, Israel, and its numerical modeling. J Geophys Res 2009;114:C09002.

26. Papadopoulos GA, Dermentzopoulos Th. A tsunami risk management pilot study in Heraklion, Crete. Nat Hazards 1998;18: 91-118.

27. Mitsoudis DA, Flouri ET, Chrysoulakis N, et al. Tsunami hazard in the southeast Aegean Sea. Coastal Engine 2012;60:136-48.

28. Waechter J, Babeyko A, Fleischer J, et al. Development of tsunami early warning systems and future challenges. Nat Hazards Earth Syst Sci. 2012;12:1923-35.

29. Schindelé F. Tsunami warning in near-field for the two large 1996 Peru earthquakes. In: Proc. Int. Conference on Tsunamis, 1998 May 26-28, Paris, France, pp 173-84.

30. Murata S, Imamura F, Katoh K, et al. Tsunami to survive from Tsunami. Advanced series on ocean engineering, vol. 32. Singapore: World Scientific; 2010.

31. Lauterjung J, Münch U, Rundloff A. The challenge of installing a tsunami early warning system in the vicinity of the Sunda Arc, Indonesia. Nat Hazard Earth Sys 2010;10:641-46.

32. Sasorova E, Korovin ME, Morozov VE,
Savochkin PV. On the problem of local tsunamis and possibilities of their warning. Oceanology 2008;48:634-45.

33. Kamigaichi 0. JMA's response to Off the Pacific Coast of Tohoku earthquake and planned improvements of tsunami warning. In: Proc. Japan-IOC/UNESCO/UNU Symposium "The Great East Japan Tsunami on 11 March 2011 and Tsunami Warning Systems: Policy Perspectives", 2012 Feb 1617, United Nations University, Tokyo, Japan. Available from: http//ioc-tsunami.org/index. php?option=com_oe\&task=viewDocument Record\&docID=8619

34. Sasaki S. The great east Japan tsunami and tsunami warning systems: policy perspectives-What happened at that time? Report from affected areas. In: Proc. Japan-IOC/UNESCO/UNU Symposium "The Great East Japan Tsunami on 11 March 2011 and Tsunami Warning Systems: Policy Perspectives", 2012 Feb 16-17, United Nations University, Tokyo, Japan. Available from: http//ioc-tsunami.org/index.php?option =com_oe\&task=viewDocumentRecord\&docI $\mathrm{D}=8606$

35. Koshimura S. The impact of the 2011 Tohoku earthquake tsunami disaster. Lesson towards tsunami-resilient communities. In: Proc. Japan-IOC/UNESCO/UNU Symposium "The Great East Japan Tsunami on 11 March 2011 and Tsunami Warning Systems: Policy Perspectives", 2012 Feb 16-17, United Nations University, Tokyo, Japan. Available from: http:/ioc-tsunami.org/index.php?option =com_oe\&task=viewDocumentRecord\&docI $\mathrm{D}=8608$

36. Suenaga M. Miracle in Kamaishi really? Disaster education in school and community. How to do it. In: Proc. JapanIOC/UNESCO/UNU Symposium "The Great East Japan Tsunami on 11 March 2011 and Tsunami Warning Systems: Policy Perspectives", 2012 Feb 16-17, United Nations University, Tokyo, Japan. Available from: http://ioc-tsunami.org/index.php? option=com_oe\&task=viewDocumentRec ord\&docID=8614

37. Tinti S, Graziani L, Brizuela B, et al. Applicability of the decision matrix of North Eastern Atlantic, Mediterranean and connected seas tsunami warning system to the Italian tsunamis. Nat Hazards Earth Syst Sci 2012;12:843-57.

38. Iwata T. Earthquake countermeasures of Shizuoka Prefecture, Japan. In: Proc. Japan-IOC/UNESCO/UNU Symposium "The Great East Japan Tsunami on 11 March 2011 and Tsunami Warning Systems: Policy Perspectives", 2012 Feb 16-17, United Nations University, Tokyo, Japan. Available from: http://ioc-tsunami. org/index.php?option=com_oe\&task= viewDocumentRecord\&docID $=8615$ 